\section{Using a Computer Spreadsheet and Compiler to Extend Growth Models to Greenhouse Growers}

\author{
George J. Wulster ${ }^{1}$
}

Additional index words. lily, Lilium longiflorum, computer, software development

Summary. A software application for the personal computer has been developed using the macro languages of Lotus 1-2-3 Release 2.2 and the spreadsheet compiler Baler XE Release 1.0E to provide Easter lily (Lilium longiflorum Thunb.) growers with a tool to track and predict various developmental stages of the crop during greenhouse forcing.

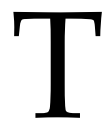
he program uses grower inputs on stage of development; i.e., emergence date, leafnumbers, etc., as well as environmental information. Equations from recently published research on lily growth and development embedded in the spreadsheet use the input variables to predict such events as visible bud date, final plant height, and days to flower. Graphs can be generated to follow the heights of up to three emergence groups, and can be adjusted easily to account for different emergence groups and/or Easter dates. The program also has a context-sensitive help system for providing detailed information concerning the limits of the software and tangentially related topics such as growth retardants.

In recent years, a considerable amount of research has been published in an attempt to model environmental effects on the phases of greenhouse forcing of vernalized Easter lilies. These phases, as summarized by Karlsson et al. (1988), consist of: I)

${ }^{1}$ Associate Professor, Department of Horticulture, Rutgers University, P.O. Box 231, New Brunswick, NJ 08903. potted vernalized bulbs prior to flower initiation; 2) plants from flower initiation to visible bud; and 3) plants from visible bud to flower opening.

The practical offshoot of this modeling research has been the publication of temperature manipulation (DIF) and crop monitoring strategies (graphical tracking). Heins and Erwin (1987) intended to supplement traditional approaches to lily height control and development. However, the changing date of Easter, different shipping dates among growers, and inherent variability among lily crops render many aspects of the available printed information (e.g., graphical tracking plots) inappropriate, not only from year to year, but from grower to grower.

The mathematical expressions relating temperature effects to the various stages of lily development are complex (Table 1) and are distributed among several professional and trade publications, rendering the body of work, as a whole, inconvenient to access and use, although considerable interest in applying it has been expressed by growers and cooperative extension personnel.

The objective of this program is to make use of the mathematical platform inherent in a computerized spreadsheet (Lotus 1-2-3, V2.2) to provide a flexible medium to allow extension personnel and lily growers to use this important information in a less-fragmented and cumbersome manner. To make the software available on the most general basis, it was compiled to a free-standing application that requires no spreadsheet software to run.

\section{System requirements}

The program runs on an IBMcompatible computer with at least $512 \mathrm{k}$ of RAM. It can be installed to a hard drive or run from either a 3.5- or 5.25inch (high-density) floppy disk drive. Driver support for a large number of printers is available for printing graphs.

\section{Program overview}

The equations from Table 1 are embedded in the spreadsheet, which makes the calculation of the equations a straightforward matter. The macro command languages of Lotus 1-2-3 and Baler XE were used to write codes for menus, program prompts to the user, verification of user input, and proper placement of input in the worksheet.
1) Estimation of visible bud date. The program allows for an estimation of visible bud date based on day and night temperatures and the average number of leaves to be unfolded within an emergence group. The display from this section (Fig. 1), uses Eq. [1] (Table 1), which calculates a leafunfolding rate (LUR) . Equation [2] (Table 1) uses this rate, the average number of leaves remaining (ANL), and the current date to estimate the date of visible bud. The ideal visible bud date is based on the assumption that visible bud should be achieved 32 days prior to the desired shipping date.

The grower may adjust day and night temperatures and their duration until the projected visible bud date is suitably close to the ideal date. Several different emergence groups and day/ night temperature regimes can be evaluated quickly in this manner and printed.

The grower inputs required are:

- Emergence group identification.

- Current date.

- Shipping date.

- Average leaves remaining for group.

- Night temperature and duration.

- Day temperature and duration.

Program output:

- Maximum weekly height curve.

- Minimum weekly height curve.

2) Growtb trading utility. This utility allows the producer to generate projected growth curves for up to three emergence groups, and input actual emergence group height measurements for comparison. Curves can be adjusted for differing emergence or shipping dates. As height measurements are made, graphs can be updated, viewed, and printed for comparing actual height to desired height, or the graph may be printed and placed in the greenhouse and marked by hand as crop height is monitored. A hypothetical graph for an emergence group for a 1992 lily crop is shown in Fig. 2. The production period length is limited to a range of 87 to 97 days. The height displayed is the plant height above the pot.

Grower inputs required:

- Emergence date.

- Sale date.

- Acceptable minimum height.

- Acceptable maximum height. 
Table 1. Equations and sources for the main calculations carried out in the Easter lily. growth and development program.

\section{Parameter}

Equation $^{2}$

Source

Daily leaf unfolding rate

Days to visible bud

Daily bud development rate

Height prediction at anthesis:

From visible bud

From initiation

Stage of bud development

Estimated days to anthesis
$[1] \mathrm{Y}=-1.77+0.0522 \times \mathrm{ADT}$

[2] ANL/LUR

[3] $-0.103658 \mathrm{E}-1+0.2615 \mathrm{E}-2 \times[(\mathrm{HDT} \times \mathrm{DT})+(\mathrm{HNT} \times \mathrm{NT})] / 24$ $-0.408527 \mathrm{E}-6 / 10 \times \mathrm{HDT} \times \mathrm{DT}^{3}-0.66292 \mathrm{E}-6 / 14 \times \mathrm{HNT} \times \mathrm{NT}^{3}$

[4] $(0.496946 \times \mathrm{DIF})+\left(0.0150561 \times \mathrm{DIF}^{2}\right)+18.01+\mathrm{VBH}$

[5] $1.4860 \times \mathrm{DIF}-0.0416 \times \mathrm{DT} \times \mathrm{NT}+1.9139 \times$ avg. temp. +25.661

[6] $(\mathrm{CD}-\mathrm{AVBD}) \times \mathrm{DBDR}$

[7] $(1 / \mathrm{DBDR})-(\mathrm{CD}-\mathrm{AVBD})$
Erwin et al. (1987)

Erwin et al. (1990)

Erwin et al. (1990)

Erwin et al. (1989)

${ }^{2} \mathrm{ADT}=$ average daily temperature $(24 \mathrm{~h}), \mathrm{ANL}=$ average number of leaves remaining, $\mathrm{AVBD}=$ actual visible bud date, $\mathrm{CD}=\mathrm{current}$ date, $\mathrm{DBDR}=$ daily bud development rate, DT $=$ day temperature $\left({ }^{\circ} \mathrm{F}\right), \mathrm{HDT}=$ day temperature duration $(\mathrm{h}), \mathrm{HNT}=$ night temperature duration $(\mathrm{h}), \mathrm{LUR}=$ leaf unfolding rate, $\mathrm{NT}=$ night temperature, $\mathrm{VBH}=$ height at visible bud (inches), DIF = average DT- average NT.

\begin{tabular}{|c|c|}
\hline EMERGENCE GROUP: Group 1 & CURRENT DATE: $02 / 12 / 92$ \\
\hline EMERGENCE DATE: 01/3/92 & PALM SUNDAY: 04/16/92 \\
\hline & LEAVES REMAINING: 44 \\
\hline CURRENT DATE: & \\
\hline IDEAL VISIBLE BUD DATE: $\quad 03 / 15 / 92$ & \\
\hline PROJECTED VISIBLE BUD DATE: $\quad$ 03/09/92 & \\
\hline PREDICTED LEAF UNFOLDING RATE: 1.74 leaves per day & \\
\hline NUMBER OF DAYS TO VISIBLE BUD: 25 & \\
\hline TEMPERATURES (F): NIGHT : $60.0 \mathrm{~F}$ & DURATION (HRS): $\quad 11.0$ \\
\hline DAY : $75.0 \mathrm{~F}$ & DURATION (HRS): \\
\hline
\end{tabular}

Fig. 1. Date of visible bud prediction based on user inputs regarding temperature settings and number of leaves remaining to unfold for 'Nellie White Easter lily.

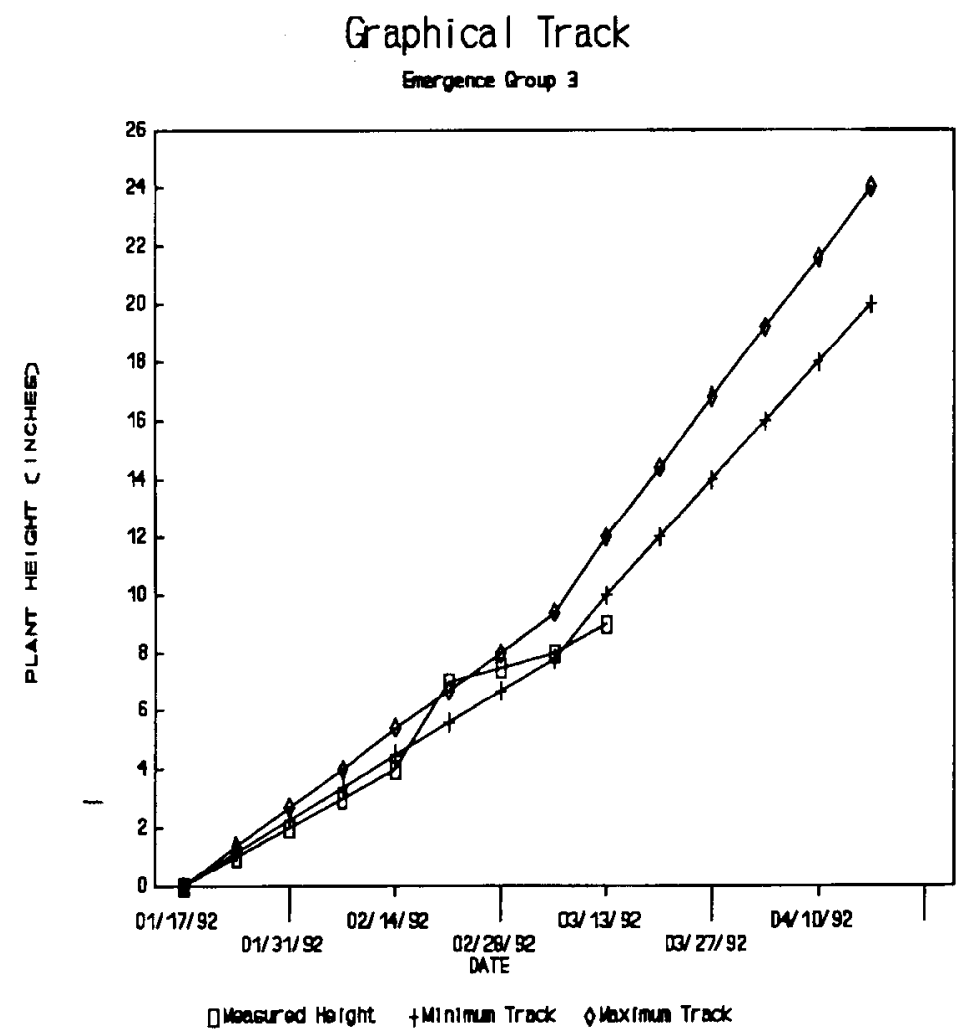

Fig. 2. Projected maximum, minimum, and measured heights (in inches) above the pot of Easter lily plants asgenerated and printed by the graphics portion of the lily growth and development program.
- Actual height measured by date.

Program output:

- Maximum weekly height curve.

- Minimum weekly height curve.

3) Estimation Official height and flowering date. Two subsections are used to estimate final height and flowering date. The Initiation to Shipping subsection (Fig. 3) provides an estimate of the most appropriate day and night temperatures to achieve a specified final height range. The output of this subsection, in conjunction with section 1 above, can be used to suggest greenhouse temperatures for appropriate leaf unfolding rates that do not lead to excessive height increases. The display from this section (Fig. 3) is based on Eq. [5] (Table 1).

Figures 1 and 3 are reproductions of actual output from the program with the day and night temperature inputs the same. It is clear that a day temperature of $75 \mathrm{~F}(24 \mathrm{C})$ and night temperature of $60 \mathrm{~F}(15.5 \mathrm{C})$ with 44 leaves (on average) to unfold will result in a sufficiently early visible bud date. Figure 3, however, indicates that plants grown at these temperature settings will be unacceptably tall; i.e., 29 inches $(73.6 \mathrm{~cm})$ projectedvs. 24 inches $(61 \mathrm{~cm})$-the maximum acceptable height entered. At this point, the grower may quickly evaluate other day/ night temperature options for the same leaf unfolding rate that would minimize an increase in final height.

The Visible Bud to Shipping subsection (Fig. 4) is designed to evaluate the impact of temperatures on final height and flower bud development rates. Height at visible bud (HVB) and Eq. [4] (Table 1) are used to predict final crop height at different day and night temperature combinations (Fig. 4). A matrix showing projected final 


\begin{tabular}{|c|c|}
\hline EMERGENCE GROUP I.D. Group 1 & CURRENT DATE: $2 / 16 / 92$ \\
\hline DESIRED HEIGHT RANGE: $20-24$ in. & DT (F): \\
\hline HEIGHT, CURRENT: $8.24-9.88$ in. & DTDUR (H): \\
\hline HEIGHT NOW: & NT (F): \\
\hline EST. FINAL HEIGHT (2): 29.51 in. & NTDUR $(H):$ \\
\hline
\end{tabular}

Fig. 3. Final height estimation of Nellie White Easter lily based on the day and night temperature settings and durations shown if applied from bud initiation until shipment.

$\begin{array}{ll}\text { EMERGENCE GROUP I.D.: GROUP } 1 & \text { CURRENT DATE: } 3 / 22 / 92 \\ \text { FLOWER DEVELOPMENT RATE: } 0.03 & \text { VISIBLE BUD DATE: } 3 / 15 / 92 \\ \text { ESTIMATED DAYS TO FLOWER: } 23.29 & \text { DT (F): } 75 \\ \text { ESTIMATED DEVELOPMENT STAGE: } 23.11 \% & \text { DTDUR (H): } 13.00 \\ & \text { NT (F): } 60 \\ \text { ESTIMATED FLOWERING DATE: } 4 / 4 / 92 & \text { DTDUR (H): } 11.00 \\ \text { DESIRED FLOWERING DATE: } 4 / 16 / 92 & \text { 10 Palm Sunday or shipping date } \\ \text { ESTIMATED FINAL HEIGHT (1): } 17.9 \text { in. } & \text { FROM VISIBLE BUD: } \\ \text { DESIRED FINAL HEIGHT RANGE: } 18 \text { TO } 24 \text { in. } & \end{array}$

Fig. 4. Flowering date and final height estimation base on user inputs of temperature regimes applied from visible bud date until shipping date of Nellie White Easter lily having a height at visible bud of 9 inches $(22.9 \mathrm{~cm})$.

heights at many visible bud heights and day and night temperature differences (DIF) can be viewed and printed (Fig. 5). This will help in establishing a day/night temperature relationship for the desired final height.

A flower bud daily development rate is also calculated (Fig. 4) using Eq. [3] (Table 1). This, in turn, is used in conjunction with visible bud date and the desired shipping date (Eqs. [6] and [7], Table 1) to show the the impact of chosen temperature regimes on flower development and plant height.

Grower inputs required:

- Emergence group identification.

- Current date. -

- Actual visible bud date.

- Day temperature and duration.

- Night temperature and duration.

- Height at visible bud.

Program output:

- Estimated days to flower.

- Estimated flowering date.

- Percent development complete.

- Estimated final height.
4) User help. Acontext-sensitive user help system is incorporated into the program. Help screens accessed from various portions of the program contain additional information regarding the program s limitations, and other factors than greenhouse temperature that may influence Easter lily height and development rates (Hammer and Hopper, 1989).

\section{Program limitations}

Many factors prior to and during forcing, as well as greenhouse forcing temperatures, have been shown to affect Easter lily crop growth and development (Hammer and Hopper, 1989; Lieth and Carpenter, 1990; Roberts et al., 1985). Consequently, projections concerning height and developmental rates based solely on the greenhouse temperature environment cannot be completely accurate. Of necessity, growth and development models are generated under precisely controlled environmental conditions and/or constant temperature regimes. In many production areas and facilities, these constant temperatures can be duplicated only partially. Consequently, the greenhouse production environment may differ significantly from the precisely controlled conditions employed to characterize mathematically the Easter lily responses to temperature.

Although limitations exist, the

\begin{tabular}{|cccccccc|}
\hline HVB & \multicolumn{7}{c|}{ Potential DIF values (F) } \\
(inches) & -15 & -10 & -5 & 0 & 5 & 10 & 15 \\
\hline 5 & 11.1 & 11.4 & 11.8 & 12.2 & 12.7 & 13.3 & 13.9 \\
6 & 12.1 & 12.4 & 12.8 & 13.2 & 13.7 & 14.3 & 14.9 \\
7 & 13.1 & 13.4 & 13.8 & 14.2 & 14.7 & 15.3 & 15.9 \\
8 & 14.1 & 14.4 & 14.8 & 15.2 & 15.7 & 16.3 & 16.9 \\
9 & 15.1 & 15.4 & 15.8 & 16.2 & 16.7 & 17.3 & 17.9 \\
10 & 16.1 & 16.4 & 16.8 & 17.2 & 17.7 & 18.3 & 18.9 \\
11 & 17.1 & 17.4 & 17.8 & 18.1 & 18.7 & 19.3 & 19.9 \\
12 & 18.1 & 18.4 & 18.8 & 19.2 & 19.7 & 20.3 & 20.9 \\
13 & 19.1 & 18.4 & 19.8 & 20.2 & 20.7 & 21.3 & 21.9 \\
14 & 20.1 & 20.4 & 20.8 & 21.2 & 21.7 & 22.3 & 22.9 \\
15 & 21.1 & 21.4 & 21.8 & 22.2 & 22.7 & 23.3 & 23.9 \\
16 & 22.1 & 22.4 & 22.8 & 23.2 & 23.7 & 24.3 & 24.9 \\
17 & 23.1 & 23.4 & 23.8 & 24.2 & 24.7 & 25.3 & 25.9 \\
18 & 24.1 & 24.4 & 24.8 & 25.2 & 25.7 & 26.3 & 26.9 \\
19 & 25.1 & 25.4 & 25.8 & 26.2 & 26.7 & 27.3 & 27.9 \\
20 & 26.1 & 26.4 & 26.8 & 27.2 & 27.7 & 28.8 & 28.9 \\
\hline
\end{tabular}

Fig. 5. Potential final height (in inches) of Nellie White Easter lily grown under neutral, positive, or negative day and night temperature differences (DIF) from a given height at visible (HVB). 
program is a step toward assisting growers in establishing temperature regimes that can provide an appropriate rate of development without unduly increasing or decreasing plant height.

In 1992, the program was used successfully to assist a New Jersey grower of 60,000 Easter lilies and a Pennsylvania grower of 10,000 lilies to make practical decisions regarding potential impacts of temperature regimes on crop growth and development. The chief discrepancy between program projections and crop performance was in the estimated days to flower from visible bud-plants actually flowered several days earlier than the program estimated. The program is a significant aid in rapidly considering temperature management practices to control the crops height and rate of development.

See the Resources Available section of this issue of HortTechnology for more information about obtaining the program.

\section{Acknowledgements}

I thank Royal Heins (Michigan State Univ., East Lansing) for his suggestions for improving the program in general, and the growth-tracking utility in particular, as well as Heinrich Lieth (Univ. of California, Davis) for using the program and offering several valuable suggestions for its improvement.

\section{Literature Cited}

Erwin, J.E., R. Heins, M. Karlsson, W. Carlson, and J. Birnbaum. 1987. Producing Easter lilies. Michigan State Univ. Ext. Bul. E-1406.

Erwin, J.E., R.D. Heins, and M.G. Karlsson. 1989. Thermomorphogenesis in Lilium longiflorum. Amer. J. Bot. 76(1):47-52.

Erwin, J.E. and R.D. Heins. 1990. Temperature effects on lily development rate and morphology from visible bud stage until anthesis. J. Amer. Soc. Hort. Sci. 115(4):644-646

Hammer, P.A. and D.A. Hopper. 1989. Modeling stem elongation of Easter lilies grown under various production schemes. HortScience 24(5):785-788.

Heins, R. and J. Erwin. 1987. Tracking Easter lily height with graphs. Grower Talk 51(8):64-65.

Karlsson, M.G., R.D. Heins, and J.E. Erwin. 1988. Quantifying temperature-controlled leafunfolding rates in Nellie White Easter lily. J. Amer. Soc. Hort. Sci. 113(1):7074.

Lieth, J.H. and P. Carpenter. 1990. Modeling stem elongation and leaf unfolding of Easter lily during greenhouse forcing. Scientia Hort. (44)149-162.

Roberts, A.N., J.R. Stang, Y.T. Wang, W.R. McCorckle, L.J. Riddle, and F.W. Moeller. 1985. Easter lily growth and development. Oregon Agr. Expt. Sta. Tech. Bul. 148. 